\title{
LA CONQUISTA DEL IMAGINARIO COLECTIVO CARTOGRAFÍA DEL DESIERTO
}

\author{
THE CONQUEST OF THE SOCIAL IMAGINARY \\ CARTOGRAPHY OF THE DESERT
}

Carolina Rodríguez | caro.rodriguez.cr@hotmail.com

Michelle Sepúlveda | jun0p@hotmail.com

Tamara Siminkowich | tamara.siminkowich@gmail.com

Facultad de Bellas Artes. Universidad Nacional de La Plata. Argentina

Recibido: 13/3/2018 | Aceptado: 20/6/2018

\section{RESUMEN}

El análisis a desarrollar sobre el mapa La Conquista del Desierto (1987) y su libro Lo Conquisto del Desierto, 1536- 1879 (1993), pertenecientes al Archivo Histórico de Geodesia, brindará una aproximación a la construcción del imaginario colectivo en las décadas de 1980 y 1990. El foco estará puesto en el análisis iconográfico del mapa con el fin de estudiarlo como artefacto cultural y nos detendremos en los aspectos gráficos y de contenido. El estudio de estos objetos puede ser una vía posible para comprender algunos aspectos de la cultura de finales del siglo XIX, como también interpretar el punto de vista ideológico y cultural que se tenía sobre la conquista a finales del siglo XX.

\section{PALABRAS CLAVE}

Cartografía; cultura visual; Geodesia; Conquista del Desierto; archivo

\section{ABSTRACT}

The analysis to be developed on the map of The Conquest of the Desert (1987) and its book The Conquest of the Desert, 1536- 1879 (1993), both belonging to the Historical Archive of Geodesia, will provide an approximation to the construction of the collective imaginary in the 1980s and 1990s. The focus will be placed on the iconographic analysis of the map in order to study it as a cultural objetc, concentrating on the graphic and content aspects. The study of these objects can be a possible way to understand some aspects of the culture of the late $19^{\text {th }}$ century, as well as interpreting the ideological and cultural point of view about the conquest at the end of the $20^{\text {th }}$ century.

\section{KEYWORDS}

Cartography; visual culture; Geodesia; Conquest of the Desert; archive 


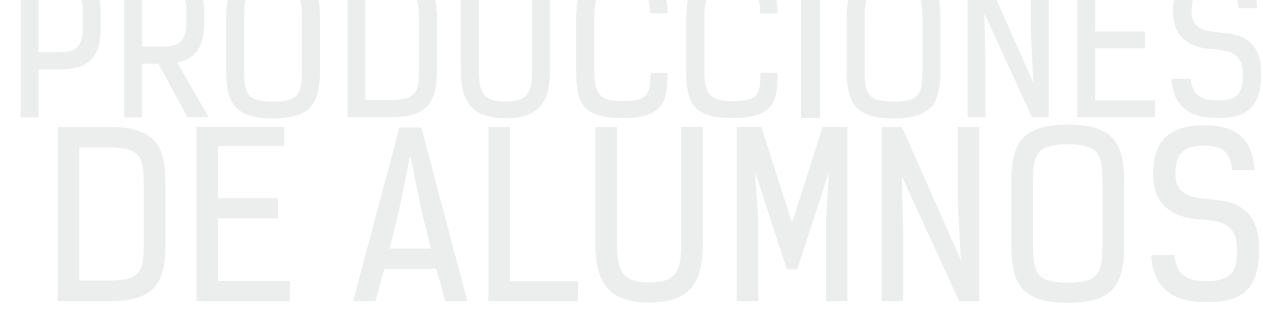

El Departamento de Investigación Histórica y Cartográfica (DIHyC) de la Dirección de Geodesia depende del Ministerio de Infraestructura y Servicios Públicos de la provincia de Buenos Aires y se encarga de preservar la documentación original del dominio de la tierra de la Provincia desde 1583 hasta 1940. Brinda información histórica y cartográfica sobre los propietarios de la tierra, donde se destaca el carácter único e insustituible de los documentos y funciona como fuente primaria de consulta. La institución atiende las demandas para el desarrollo de actividades públicas o privadas de profesionales, investigadores, estudiantes de diferentes disciplinas y especialidades, como la historia, la sociología, la arquitectura, la cartografía histórica, el urbanismo y la agrimensura. Los documentos que se archivan en este lugar se dividen en tres grandes grupos: mensuras, mapas e inscripciones de dominio de vendedores y compradores. También cuenta con una biblioteca que reúne censos, como reseñas históricas y antecedentes sobre el origen de pueblos y partidos, entre otros.

Al analizar cómo ha evolucionado el concepto de archivo en nuestra contemporaneidad, Andrea Giunta (2010) manifiesta una nueva era para la noción de archivo, donde la democratización y la digitalización imperan. Para Giunta, el campo de aplicación de lo que involucra la noción de archivo se ha expandido y ha desatado una auténtica fiebre. El uso intensivo y creativo de los documentos es uno de los rasgos sobresalientes del arte más contemporáneo y ha sido analizado desde perspectivas que le otorgan densidad teórica, carácter innovador e, incluso, un sentido utópico a dichas prácticas. Los archivos han sido sacralizados y, al mismo tiempo, desordenados al poner en cuestión el canon, las instituciones y las historias construidas. Las nuevas poéticas/políticas de archivos se basan en una palabra clave: democratización.

Por una parte, la idea de accesibilidad opaca la posibilidad de que el archivo como tal no exista si no está ligado a una memoria acumulativa que la investigación desclasifica y descalza para proyectarle un nuevo orden o una relación con otros documentos; en otras palabras: el hecho de que cada investigador con su proyecto construye un nuevo registro. Por otra parte, la noción de archivo en la historia del arte plantea pensar en otro tipo de historia, una que confronte las imágenes con los documentos (y viceversa), y también constituye a una manera de ensamblar la historia del arte lineal.

\section{LA CONQQUISTA DEL DESIERTO: MAPA Y LIBRO}

Un documento cartográfico y un libro nos relatan visual y textualmente la Conquista del Desierto desde el año 1536 hasta el año 1879. El mapa impreso 


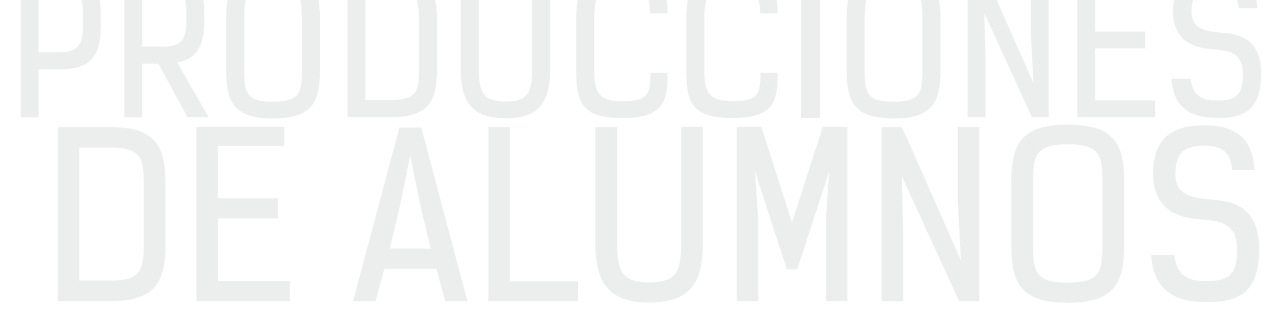

en papel mide $105 \times 75 \mathrm{~cm}$ y tiene una mayor variedad de colores, en comparación con la cartografía producida en litografía. El libro La Conquisto del Desierto, 1536-1879 (1993) funciona como un anexo al mapa, tiene 118 páginas y en su tapa y contratapa se distingue en color marrón un fragmento del mapa del noreste de la provincia de Buenos Aires.

El mapa [Figura 1] fue editado por la Dirección de Geodesia en el año 1979, con motivo del centenario de la expedición del General Julio Argentino Roca al Río Negro. Los objetos a estudiar corresponden a la segunda edición ampliada de 1987. La cartografía presenta más de treinta ubicaciones de fortines, tratados y combates, entre otros. El libro complementa y explica cada uno de los puntos y hechos señalados, y contiene un glosario de los términos propios de la época de la conquista y de la toponimia bonaerense. La nueva carta representa seis etapas y cada una se indica con un color diferente: Época colonial, de 1536-1810 (naranja); Época independiente hasta 1850 (rojo); De Caseros a 1868 (amarillo); Presidencia de Sarmiento hasta 1872 (violeta); Conquista del Desierto 1879 (verde) y Cartografía actual (marrón).

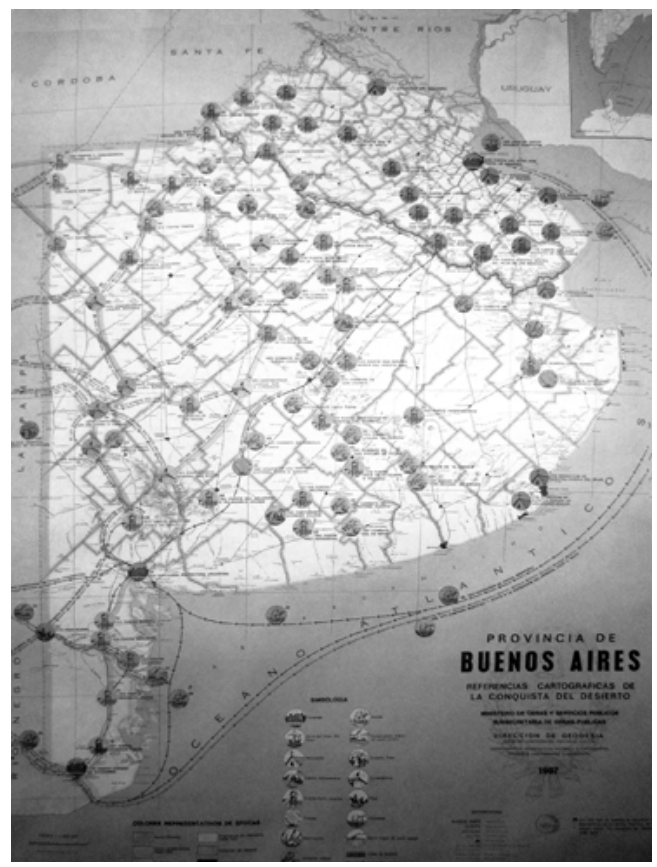

Figura 1. Referencias cartográficas de la Conquista del Desierto (1987), Luis S. Romano y Eduardo J. Suñé. Archivo Histórico de Geodesia 


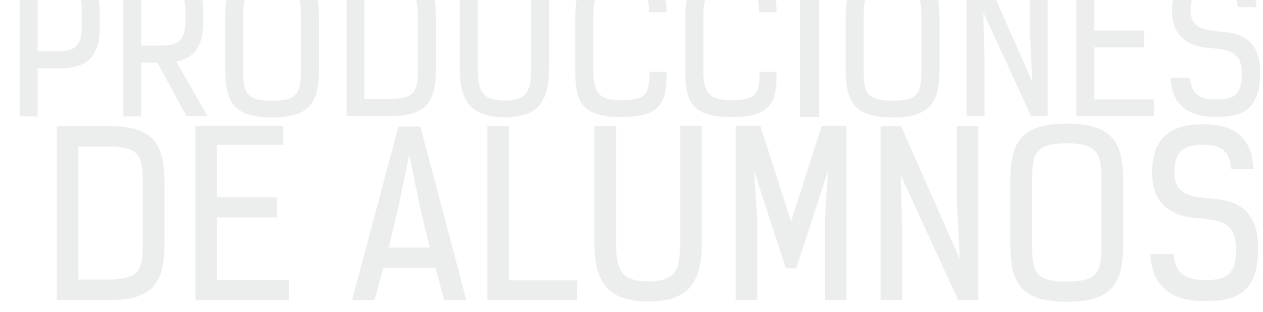

En el año 1987 se imprimieron tres mil copias de este mapa y del libro, una cantidad que nos hace pensar no solo en una difusión institucional, particular o privada, sino que se podría tratar de una difusión provincial. El prólogo del libro expresa que la primera edición de 1979 tuvo tanto éxito que decidieron hacer una segunda en 1987. Sin embargo, la segunda edición impresa en 1993 no se difundió. Aunque la dirección de Geodesia concretó el trabajo para ponerlo a disposición de los docentes (como apoyo a su tarea de enseñar a las futuras generaciones la verdadera' integración del territorio de nuestra provincia) esta segunda edición no se difundió y se resguardó en el Archivo Histórico de Geodesia.

Los objetos fueron confeccionados por la División Cartográfica de Geodesia, que también preparó los logotipos representativos que los ilustran. La División Publicaciones se ocupó de diagramar y dar forma a este folleto. En la esquina inferior derecha del plano se da créditos a los cartógrafos Luis S. Romano y Eduardo J. Suñé, quienes fueron los encargados de la cartografía y de la ilustración, acompañados por Domingo de Pérez. Muchos de los mapas de la provincia de Buenos Aires que aún cuelgan en las oficinas públicas, los dibujó el Sr. Luis Romano con tinta china en papel vegetal, junto con artesanos, como Edmundo Gutiérrez, Emilio Rapisarda, Eduardo Suñé, Damián Pérez, Nidya Vega Segovia, Edgardo Mannino y Elvira Hours, la que hacía los colores de los mapas en una muestra de acuarela que se mandaba a la imprenta (López Mac Kenzie \& Bellini, 2012).

Los cartógrafos, antes de los avances de la tecnología que renovaron la disciplina desde la segunda mitad del siglo XX - foto aérea, foto satelital y computación para procesar esa información-, se nutrían de datos topográficos enviados desde el terreno por agrimensores y se tardaba, aproximadamente, un año en dibujar un mapa. La calidad de estos mapas era muy diferente a nuestra carta, la cual está intervenida e impresa digitalmente. Por lo tanto, el mapa pierde toda característica artesanal en su modo de producción, en comparación con los mapas realizados con la técnica litográfica.

Aunque el material ha sido reservado, visto como un objeto raro ${ }^{2}$ y consultado solamente en las instancias del Archivo de Geodesia, también ha servido como fuente importante para varios libros y estudios. Entre ellos se puede nombrar al libro Viejos y nuevos estudios etnohistóricos. Relociones interétnicas y lo emergencio de uno culturo mestizo en América del Sur (1999), compilado por María M. González Coll. Otro ejemplo es El agrimensor del siglo XIX (2016), de Alberto R. Fontanarossa, quien aprovechó para agradecer al Archivo Histórico de la Dirección de Geodesia la colaboración en su trabajo, ya que le facilitó la referencia cartográfica de la Campaña del Desierto editada en 1987.

Arte y cartografía, con una larga trayectoria de mucha atracción, se proyectan en este mapa que ostenta, además, la particularidad de ser ilustrado. Junto con
1 En el apartado titulado «La historia desde el poder» desarrollaremos la problemática de la verosimilitud y la imagen como construcción ideológica.
2 Se considera raro el documento, tanto el mapa como el libro, ya que nunca se difundieron oficialmente y se resguardaron en el Archivo de Geodesia. Por tanto, el contacto con los documentos solo se puede llevar a cabo visitando el lugar y pidiéndolos personalmente. A su vez, hemos encontrado que el libro se vende en internet como objeto raro. 
el mapa, el libro abunda en sucesos narrativos sobre los hechos de la Conquista del Desierto y se constituye, así, en una fuente complementaria para indagar las vinculaciones entre texto e imagen, la relación entre el registro visual y el acontecimiento y la construcción de los imaginarios colectivos.

\section{LA HISTORIA DESDE EL PODER}

Los mapas como medios de conocimiento no siempre se constituyeron como artefactos culturales u obras de síntesis gráfica. Según Sandra Szir (2016), los lazos entre arte y mapas en la historia del arte han sido estudiados en torno a los siguientes problemas:

El reconocimiento estético de los elementos ornamentales e iconográficos en los mapas; el papel que han cumplido los artistas en la producción de mapas; el impulso de mapear la representación del entorno en algunos artistas y el análisis de elementos como el color, la letra y los símbolos (p. 58).

Estos nuevos estudios, a la vez, «se deben a los aportes de los estudios visuales, donde la historia del arte quedó habilitada para cruzar las fronteras tradicionales y abordar otros medios y artefactos visuales» (Szir, 2016, p. 59). De esta manera, se realizan lecturas transversales de artefactos visuales -el mapa es uno de ellosque ligan los campos de las imágenes con los modos de producción, circulación y recepción y, también, con modalidades de visualidades y de representación que son expresados en diversas materialidades y soportes. Por lo tanto, la imagen ya no es una construcción social de lo visual (en el sentido ilustrativo), sino que las imágenes ahora son una construcción visual de lo social, construyen un significado. Definen un nuevo espacio discursivo examinado por sus sentidos y sus modos de definir experiencias visuales en contextos históricos concretos.

La cartografía no solo se trató de un documento visual que describiera algún territorio y ambiente, sino que Szir (2016) agrega también que los mapas

funcionan como obras de síntesis gráfica y en tanto imágenes, evocan complejos sentidos y respuestas, y registraron por lo tanto mucho más que información fáctica acerca de eventos y lugares particulares: han profundizado y expandido la conciencia en muchas sociedades; han construido representaciones de espacios reales y míticos; han actuado como instrumentos de comunicación, vías hacia la imaginación y el desarrollo de metáforas, bases de memoria, instrumentos analíticos o signos de poder religioso o político (p. 57). 
Esta visión encierra un problema teórico que interpreta el paisaje y la producción cartográfica como prácticas ligadas a la compleja construcción y comunicación del conocimiento espacial, poderosamente conectadas con la vida política, social, cultural y económica. Las narrativas anexas del libro señalan a este mapa como una descripción documental de acontecimientos y de esta porción de terreno; sin embargo, al estudiar el material se comprende como una visión particular de este, ideológica y política.

De esta manera, se puede afrontar el objeto desde la problemática de la verosimilitud y la imagen como construcción ideológica. El mapa pinto o representa la realidad de la Conquista del Desierto, pero ¿cómo sabemos si realmente se muestra lo sucedido? Esto se debe a la noción de archivo como ley, donde Michel Foucault (1979) señala que el archivo es la ley de lo que puede ser dicho, se trata de un sistema que rige la aparición de los discursos como acontecimientos legítimos. De esta manera, nuestro documento funciona como una orla del tiempo que rodea nuestro presente y limita nuestra mirada sobre el hecho -en este caso la Conquista del Desierto-; por tanto, esta noción de acontecimiento le entrega densidad histórica al suceso (Foucault, 1979). A su vez, existe una demanda de verosimilitud en la imagen, donde el plano y el libro se imponen en esta búsqueda como verdad y ley.

De esta manera nos acercamos a la idea y a la concepción que se tiene sobre los hechos y se expresa en los objetos. Como es un documento legítimo del gobierno, no es posible que tenga una opinión alternativa, sino que debe ser oficial. Con alternativa nos referimos, por ejemplo, al libro Uno guerro infome. La verdadera historio de la Conquisto del Desierto (2015), de Andrés Bonatti y Javier Valdez, que cuenta la triste resistencia indígena durante la Conquista del Desierto. Por el contrario, el libro La Conquista del Desierto 1536-1879 se presenta con un tono de alabanza a los héroes nacionales y a los esfuerzos que hizo el ejército en la guerra contra los indios. Al referirse a los pueblos nativos, hace un análisis sobre sus técnicas de guerra al implementar el caballo, sus hazañas en la destrucción de asentamientos, matanzas, violaciones y raptos, pero no menciona nada de sus culturas, costumbres y orígenes, o sus esfuerzos contra la cuestión del blanco, como se refieren los autores en el libro citado.

Asimismo, podemos ubicar a nuestro mapa en ese amplio repertorio icónico de la cultura de masas, donde puede ser aceptado como un hecho y ser consumido, mucho más si los valores simbólicos que transfiere -ya sea el mapa o el libroestán en un dispositivo completamente diferente al de los tradicionales medios de comunicación. En este sentido, un punto vista claro sería que a las Bellas Artes como institución ya no se les puede conceder el principal papel de transmitir los mitos o pensamientos e ideologías en la sociedad. 
Desde esta reflexión de la recepción, podemos acentuar los usos instrumentales del mapa y el libro correspondientes, pertenecientes ahora a la cultura visual y ofrecerlos como maneras apropiadas para afrontar las guerras culturales. Así pues, el poder que conlleva la imagen (el mapa) para la creación de un imaginario social, la construcción de diferentes pensamientos y de ideas y la transferencia de varios significados y símbolos no se podría llevar a cabo sin el discurso, en este caso, el libro que tiene de anexo. En este sentido, en la actual Historia del Arte se inician planteamientos que afrontan estas cuestiones:

\footnotetext{
[...] las relaciones entre la imagen y los discursos descriptivos, las interferencias entre el texto como escritura y el cuadro como figura, el funcionamiento de los signos, las significaciones culturales y hasta las «ideologías imaginadas»; 0, desde una perspectiva pluridimensional, los poderes de las imágenes, que parecen anunciar las tensiones que se suscitarán después entre las representaciones verbales y visuales (Marchán Fiz, 2005, p. 77).
}

\section{EL MAPA Y SUS CUALIDADES GRÁFICAS}

A fin de considerar el mapa al que se hace referencia e interrogarlo como representación y también como artefacto, debe aludirse a los aspectos tanto de contenido como gráficos. En la referencia cartográfica de la Conquista del Desierto se manifiestan en forma combinada la representación de los registros de medidas (latitud, longitud y escala) y sus correlatos gráficos, junto con una serie de elementos que se corresponden con la información histórica narrativa del libro anexado.

El plano presenta quince descripciones visuales de los hechos y los lugares de la Conquista [Figura 2], escenas que manifiestan los propósitos del mapa y parte de las preocupaciones del dominio político y cultural del hombre blanco.

Dos de estas imágenes hacen alusión a los habitantes nativos de la zona (combate y toldería) y todas las demás se refieren a edificios (fuertes y fortines), embarcaciones, pasos, campamentos y comandancias del ejército, e incluso a la destrucción de los asaltos de los malones ${ }^{3}$ y los tratados de paz ante estas pérdidas. Las pequeñas ilustraciones están constituidas de forma monocromática y con una técnica de planos y líneas que crean la imagen mediante el contraste entre negro y blanco. Las características del relieve de las montañas corresponden a vistas oblicuas que rompen también con la planimetría general. Además de los elementos cartográficos, se observa una serie de rasgos que están constituidos por las indicaciones añadidas para orientar al lector: nombres, números, etiquetas, escalas, título y sello.
3 El glosario del anexo del mapa define malón como la invasión de indios cuya finalidad principal era robar ganado en las estancias fronterizas. También atacaban las poblaciones, en represalias por las acciones que el ejército realizaba contra sus tolderías o por la falta de cumplimiento de los pactos celebrados con el gobierno (Ministerio de Obras y Servicios Públicos. Dirección de Geodesia, 1993, p. 103). 


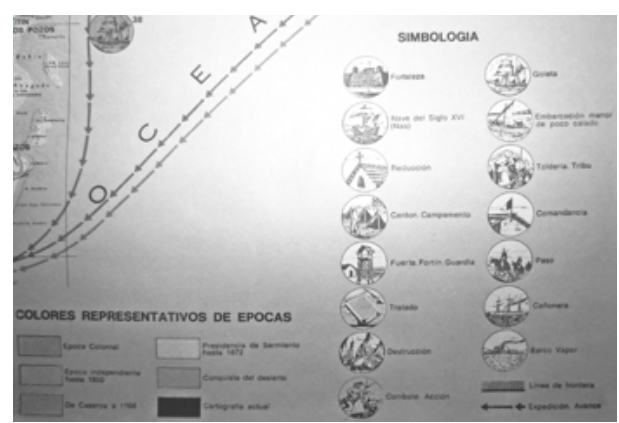

Figura 2. Referencias cartográficas de la Conquista del Desierto (detalle), Buenos Aires, (1987). Archivo Histórico de Geodesia

En la esquina inferior derecha del mapa se encuentra el escudo de la República Argentina y sobre este está escrita la provincia, el título del mapa y las instituciones encargadas de su producción [Figura 3]. Más abajo se encuentra el título Referencias, en el que se indica una serie de signos y tipologías para diferenciar localidad, partido, estación, cerros y cotas. El estilo de las letras y los títulos es una tipología computarizada, en comparación con las letras, los bordes y los títulos de los mapas hechos en litografía, que requerían de la presencia de artesanos diestros y de letristas profesionales.

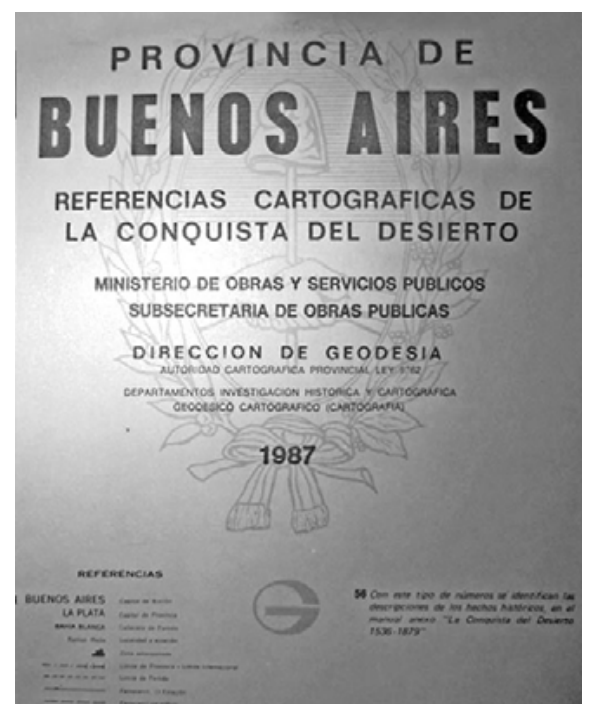

Figura 3. Referencias cartográficas de la Conquista del Desierto (detalle), Buenos aires, (1987). Archivo Histórico de Geodesia 
Las montañas (en la zona de Mar del Plata hasta Olavarría y la zona de Coronel Pringles hasta Pigüé) están delineadas individualmente con sus flancos sombreados, lo que aporta un aspecto de relieve tridimensional, con perfiles indistintos que no brindan información de tamaño y dan una idea de naturaleza de área como impresión topográfica general.

En la simbología expresada por la carta [Figura 2] se muestra la fortaleza, la nave del siglo XVI, la reducción, ${ }^{4}$ el cantón ${ }^{5}$ o el campamento, el fuerte, el fortín o la guardia, el tratado, la destrucción, el combate, la goleta, la embarcación menor de poco calado, la toldería, ${ }^{6}$ la comandancia, el paso, la cañonera y el barco a vapor.

Las imágenes que nos interesan son la representación del combate [Figura 4] y la toldería [Figura 5]. En estas descripciones se muestra la vida de los nativos en las tierras de la pampa.

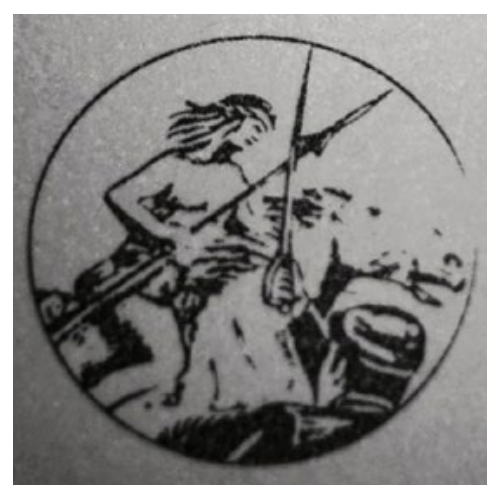

Figura 4. Referencias cartográficas de la Conquista del Desierto, Buenos Aires (1987). Detalle de la representación de combate o acción. Archivo Histórico de Geodesia

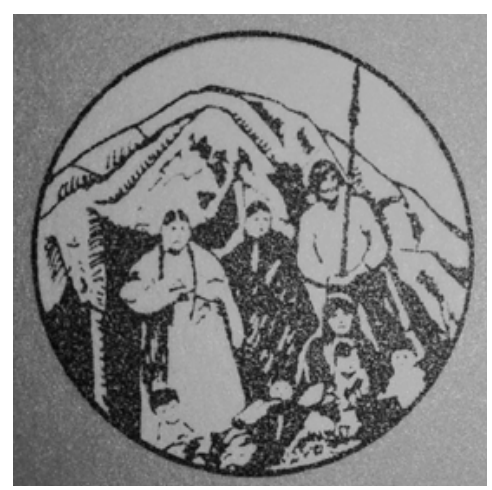

Figura 5. Referencias cartográficas de la Conquista del Desierto, Buenos Aires (1987). Detalle de la representación de la toldería o la tribu. Archivo Histórico de Geodesia
4 Se denominaba así a los pueblos de indios que habían sido sometidos y eran adoctrinados en la fe religiosa por misioneros (Ministerio de Obras y Servicios Públicos. Dirección de Geodesia, 1993, p. 107).

5 Punto fortificado de menor importancia que el fuerte (Ministerio de Obras y Servicios Públicos. Dirección de Geodesia, 1993, p. 95).

6 Conjunto de tiendas de campaña o todos en que vivían los indios (Ministerio de Obras y Servicios Públicos. Dirección de Geodesia, 1993, p. 109). 
Podemos encontrar dos referencias de toldería: la primera de la época De Caseros, en la zona de Los Toldos que representa la Tapera de Díaz, Tribu de Coliqueo-1862; y la otra de la época de la Conquista del Desierto, ubicada en el Departamento Atreuco, en la actual provincia de La Pampa, describe las Salinas Grandes (Tolderías de Calfucura). En cuanto a las notas de combate, se mencionan diecisiete que varían entre las cinco épocas.

En el signo del combate o la acción se puede observar a un cacique -0 integrante de algún malón- montado sobre un caballo y portando una lanza en su mano derecha. En un primer término se ve la cabeza de un soldado, está de espaldas levantando una espada con su mano derecha. Las armas levantadas por los dos personajes expresan el símbolo oficial para representar el combate: las espadas cruzadas. En la ilustración que figura el combate podemos ver una representación del indio que es común dentro de la iconografía de la pintura del siglo XIX. En este caso, si comparamos la figura del cacique de nuestra ilustración con las figuras que se muestran, por ejemplo, en la pintura La vuelta del malón (1892), de Ángel Della Valle [Figura 6], o El malón (1945), de Mauricio Rugendas [Figura 7], podemos

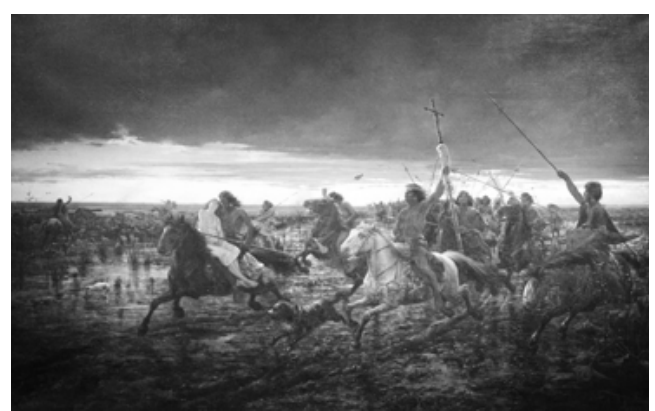

Figura 6. La vuelto del malón (1892), Ángel Della Valle. Museo Nacional de Bellas Artes, Argentina

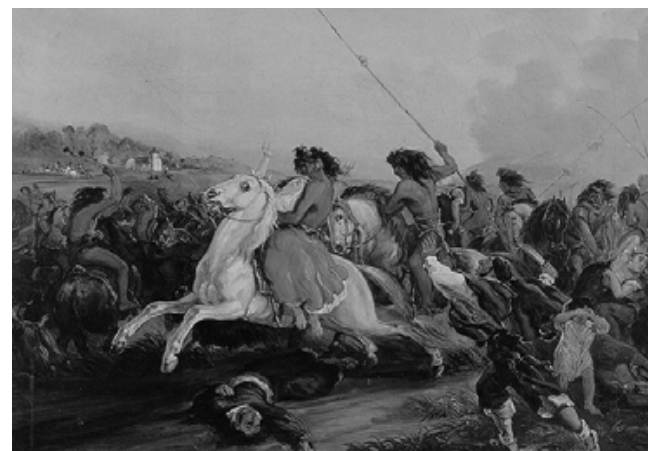

Figura 7. El malón (1845), Mauricio Rugendas. Museo Nacional de Bellas Artes, Chile 
observar similitudes. Nuestro personaje se muestra con el torso desnudo, con un taparrabo, un cintillo en su cabellera larga y alocada, y porta su lanza de la misma manera que vemos a los personajes en las pinturas. Probablemente, se haya usado como fuente la Iconografía de Potogones (1979), de Néstor Tomás Auza y Juan Mario Raone, para la construcción de las imágenes. Los autores de este libro han recurrido al grabado, al dibujo, a la fotografía, a los planos y a la pintura para mostrar la evolución de los patagones dominados por los españoles (esta fuente se encuentra citada en el libro anexo al mapa).

Por otro lado, en la imagen de la toldería o tribu [Figura 5] se muestra a una familia nativa que posa frente a su toldo. Así pues, creemos haber encontrado la fuente de inspiración para esta ilustración: se trata de una fotografía de la familia del cacique tehuelche septentrional Gabriel Manikiken, frente a su toldo de pieles de guanaco, en la provincia de Chubut, datada en 1909, la cual se encuentra en el Archivo General de la Nación [Figura 8]. En la fotografía podemos ver al cacique Manikiken parado entre su familia, integrada por tres mujeres mayores y siete menores. En el caso de la ilustración, se tomó un detalle de la fotografía y se la traspasó al dibujo. Sin embargo, el ilustrador se tomó la libertad de acomodar al cacique en la composición y de sacar a una figura. De esta manera, podemos observar a las mismas mujeres - una destaca por sus largas trenzas- y niños sentados a sus pies, mientras que se agrega a Manikiken en el lado derecho sosteniendo una lanza, la cual no existe en la imagen original. No podemos ignorar este detalle del arma, ¿cuál habrá sido la intención del ilustrador al agregar la lanza en la composición? Tampoco pasamos por alto que la tribu representada no tuvo relación con los acontecimientos que apuntan el mapa y el libro, que perteneció a otro territorio y que sobrevivió más allá de la Conquista.?

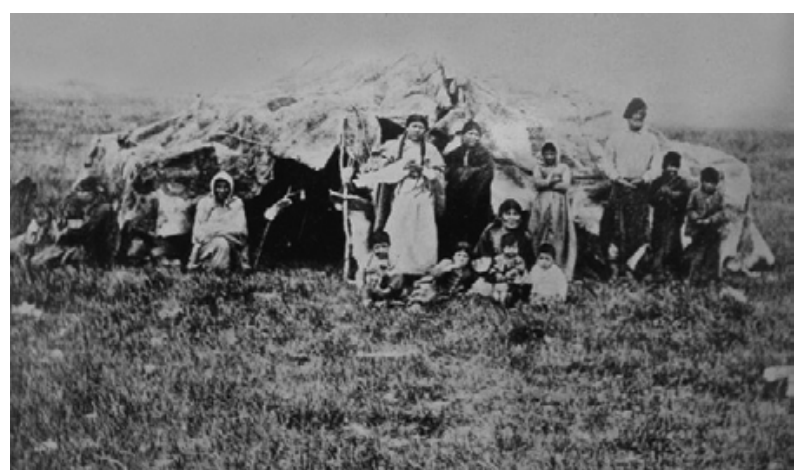

Figura 8. Toldo de pieles de guanaco de modelo cupuliforme, perteneciente al cacique tehuelche septentrional Gabriel Manikiken, presente en la fotografía con su familia en Chubut (1909). Archivo General de la Nación
7 El cacique falleció a principios de la década del veinte. Sus hijos varones no dejaron descendencia, y las hijas mujeres se unieron con hombres blancos de origen alemán y español. El apellido Manikiken se extinguió (Aguado, 2003). 
La atención a los signos utilizados para registrar y comunicar información en la referencia cartográfica de la Conquista del Desierto, comparada con otras cartas geográficas que se encuentran en el Archivo del DIHyC de la Dirección de Geodesia, indica una cierta diversificación de los rasgos debido notablemente a su modernización. Sin embargo, el croquis de las operaciones del ejército del sud y de la comisión Bahía Blanco en la campaña contra los indios desde octubre de 1857 y agosto de 1858, de 1909 [Figura 9], presenta, con respecto al anterior, visibles similitudes en algunos logotipos e imágenes, como también en la visualidad del territorio y la ubicación. Por ejemplo, el combate en el croquis se presenta con las típicas espadas cruzadas, y en el mapa analizado también se alude a esta representación. Esta similitud puede estar vinculada con las reglas institucionales para cartógrafos. ${ }^{8}$ El Monual de Signos Cartográficos (Instituto Geográfico Nacional \& Ministerio de Defensa, 2010) señala que el lugar de combate se representará con el signo 193 (espadas cruzadas) y el punto de situación será donde se cruzan las hojas de las espadas, con una orientación hacia el norte.

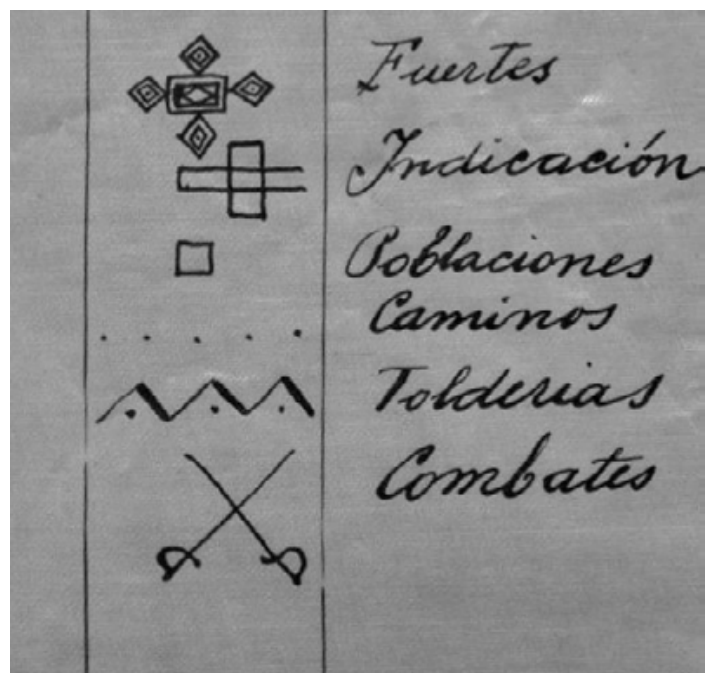

Figura 9. Croquis de las operaciones del ejército del sud y de la comisión Bahía Blanco en la campaño contra los indios desde octubre de 1857 y agosto de 1858 (1909). Archivo Histórico de Geodesia

No obstante, a la imagen de combate en nuestro mapa se le suma un contexto mediante el protagonismo de las figuras que deja al nativo como el atacante y al soldado como el defensor. Se debe a la implementación del plano, a la dirección, al tamaño y al recorte de las figuras dentro del espacio circular de la imagen. Esto deja al indio de frente y con una mayor visualidad que el soldado, al que observamos de
8 En 1826 se había creado en Buenos Aires el Departamento Topográfico. 
espaldas y solo vemos su cabeza y su brazo atacante. De igual manera, en la descripción de la tribu, la decisión del ilustrador al agregar al cacique dentro de la composición cargando una lanza puede ser una estrategia visual para exhibir la imagen del jefe de familia o tal vez quiso reforzar -aún más, el carácter bélico del indio-.

De acuerdo con la cantidad de información expresada y como una forma de organizarla, los signos podrían agruparse en dos categorías: esenciales y detalles. Los esenciales serían los que describen los acontecimientos, los asentamientos, los objetos y el transporte marítimo, como también las líneas de frontera y las flechas de expedición, todos estos ligados al uso de los colores de épocas. Estos símbolos, más que describir la topografía y el paisaje, se encargan de describir y de representar acontecimientos y objetos en torno a la Conquista del Desierto. Los detalles, en cambio, proveen una información más general y de carácter cualitativa, como por ejemplo, las zonas amanzanadas, los límites de provincia y de partido, el ferrocarril, los cerros y las cotas. La mayor parte de los símbolos esenciales tienen un carácter pictórico, mientras que los símbolos de detalle se muestran más esquemáticos, como los puntos y guiones que forman las líneas de los límites fronterizos y los ferrocarriles. Las imágenes que se relacionan con los pueblos nativos e ilustran el impreso del cual nos ocupamos en este artículo pertenecen a la primera categoría. Las imágenes que describen a los habitantes de la región pampeana y sus costumbres construyen, culturalmente, el lugar representado y se convierten en notas esenciales del plano en cuestión.

\section{CONSIDERACIONES FINALES}

Respecto de las potencialidades del archivo y del trabajo con los documentos, Andrea Giunta (2010) lo define como:

\footnotetext{
Una situación de aprendizaje, abren una posibilidad de comunicar y de intercambiar visiones. Son un espacio de diálogo, un espacio en el que unos escuchan a los otros e intercambian perspectivas y preguntas sobre su propia práctica. Entiendo el archivo como un espacio abierto en el que uno contempla, discute y debate. Lo concibo como un proceso, como algo incompleto que es reforzado por cada nueva experiencia del presente (p. 5).
}

Con respecto a los objetos estudiados, considerar a sus productores intelectuales y materiales nos conduce a poner atención en los procesos de producción, en la manera en la que los actores sociales interactúan y en los efectos que estos 
intercambios pueden tener en el resultado gráfico y textual. Estos acervos han servido como fuentes importantes para diferentes tipos de trabajos investigativos, sirviéndose de su carácter de documento único e indispensable. Quedan muchos interrogantes y vías abiertas a futuros trabajos sobre las vinculaciones entre texto e imagen y sobre la relación entre el registro visual y el acontecimiento.

Vimos cómo desde el poder se puede manejar la historia, la ideología política y cultural mediante documentos que sirven como ley. De esta manera, las ilustraciones e imágenes del mapa y el texto del libro aparecen como una síntesis de los tópicos que circularon como justificación de la Campaña del Desierto de Julio A. Roca en 1879 y se impusieron como la verdad simbólica de los términos de la conquista y del despojo. Se deben mencionar, también, los aportes que han hecho los estudios de la cultura visual, que permiten ver a estos artefactos y documentos como verdaderas representaciones de espacios reales y míticos, que actúan como instrumentos de comunicación y, lo que nos concierne, como signos de poder político.

\section{REFERENCIAS}

Aguado, A. (2003). La historia desconocida de tehuelches y mapuches en el suroeste del Chubut. Las tribus y reservas de Kánkel, Quilchamal, Maniqueque, Sacamata, Nahuel, Tracaleu y Tramaleo. La Bitácora Patagónica, 20. Recuperado de http://patagoniarelatada.ar.tripod.com/tribusseng.html

Archivo General de la Nación. (1909). Familia del cacique tehueche septentrional Gabriel Manikiken [Fotografía de archivo]. Archivo General de la Nación.

Archivo Histórico de Geodesia. (1909). Croquis de las operaciones del ejército del sud y de la comisión Bahía Blanca en la campaña contra los indios desde octubre de 1857 y agosto de 1858 [Fotografía de archivo]. Archivo Histórico de Geodesia.

Auza, N. T.; Raone, J. M. (1979). Iconografía de Patogones. Buenos Aires, Argentina: Marymar.

Bonatti, A.; Valdez, J. (2015). Uno guerro infome. Lo verdadero historio de lo Conquisto del Desierto. Buenos Aires, Argentina: Edhasa.

Della Valle, A. (1892). Lo vuelto del malón [Pintura]. Buenos Aires, Argentina: Museo Nacional de Bellas Artes. 
Fontanarossa, A. R. (2016). El agrimensor del siglo XIX. Buenos Aires, Argentina: s/d.

Foucault, M. (1979). El enunciado y el archivo. En Lo arqueología del saber (pp. 131-177). Ciudad de México, México: Siglo XXI.

Giunta, A. (2010). Archivos. Políticas del conocimiento en el arte de América Latina. Errata. Revisto de Artes Visuales, 1(1), 20-38.

González Coll, M. M. (1999). Viejos y nuevos estudios etnohistóricos. Relaciones interétnicas y lo emergencia de una cultura mestiza en América del Sur. Bahía Blanca, Argentina: Universidad Nacional del Sur.

Instituto Geográfico Nacional, Ministerio de Defensa (2010). Monual de signos cartográficos. Buenos Aires, Argentina: Instituto Geográfico Nacional.

López Mac Kenzie, J.; Bellini, J. M. (2012). Luis Romano, embotellador de orillas. La Pulseada, 102. Recuperado de http://www.lapulseada.com.ar/site/?p=3706

Marchán Fiz, S. (2005). Las artes ante la cultura visual. Notas para una genealogía en la penumbra. En J. L. Brea, Estudios Visuales. La epistemología de la visualidad en la era de la globalización. Madrid, España: Ediciones Akal.

Ministerio de Obras y Servicios Públicos. Dirección de Geodesia (1993). Lo Conquisto del Desierto 1536 - 1879. Buenos Aires, Argentina: Dirección de Impresiones del Estado y Boletín Oficial.

Romano, L. S.; Suñé, E. J. (1987). Referencias cartográficas de la Conquista del Desierto. La Plata, Argentina: Archivo Histórico de Geodesia.

Rugendas, M. (1845). El malón [Pintura]. Santiago de Chile, Chile: Museo Nacional de Bellas Artes.

Szir, S. (2016). Litografía, geografía y otras grafías. Acerca de los primeros mapas impresos en Buenos Aires. En Szir, S. (coord.), Ilustrar e imprimir. Una historia de la culturo gráfica en Buenos Aires, 1830 - 1930. (pp. 298-315). Buenos Aires, Argentina: AMPERSAND. 